\title{
Isolation, Fractionation, and Identification of Sucrose Esters from Various Oriental Tobaccos Employing Supercritical Fluids*
}

\author{
by \\ Mehdi Ashraf-Khorassani ${ }^{1}$, Negin Nazem ${ }^{1}$, Larry T. Taylor ${ }^{l}$, and William M. Coleman,III ${ }^{2}$ \\ ${ }^{1}$ Department of Chemistry, Virginia Tech, Blacksburg, VA 24061-0212, USA \\ ${ }^{2}$ R. J. Reynolds Tobacco Company, Winston Salem, NC 27102-1487, USA
}

\begin{abstract}
SUMMARY
Isolation, fractionation, and identification of sucrose esters from aged oriental tobacco employing supercritical fluids have been completed. Underivatized sucrose ester-rich extracts were obtained using supercritical $\mathrm{CO}_{2}$ at densities greater than $0.73 \mathrm{~g} / \mathrm{mL}$. Lower density $\mathrm{CO}_{2}$ provided extracts with notable amounts of tobacco derived material; yet, no detectable sucrose ester content. Preparative supercritical fluid chromatography (SFC) provided for an additional purification of the sucrose ester-enriched fraction after column optimization. Structural assignments of the SFC fractions were facilitated using gas chromatography/mass spectrometry (GC/MS) accompanied by $N, O$ bis(trimethylsilyl)trifluoroacetamide-dimethylformamide (BSTFA-DMF) derivatization of the free hydroxyl groups and high performance-liquid chromatography/mass spectrometry (HPLC/MS). From a relative quantitative perspective regardless of tobacco type, sucrose esters having an acetyl group on $\mathrm{C}_{6}$ of the glucose function (Group III) were in higher concentration compared to both the concentration observed for sucrose ester of Group I (acetyl group on $\mathrm{C}_{3}$ of fructose) and sucrose ester of Group II (no acetyl group on either glucose or fructose). Saturated fatty acid constituents were found to range from a maximum total of 18 carbons to a minimum total of 13 carbons. Unsaturated and isomeric fatty acid homologues were detected within the Group II sucrose ester. [Beitr. Tabakforsch. Int. 23 (2008) 32-45]
\end{abstract}

\section{ZUSAMMENFASSUNG}

Sukroseester aus gealtertem Orienttabak wurden mittels superkritischer Fluide isoliert, fraktioniert und identifiziert. Nicht derivatisierte Extrakte, die reich an Sukroseester waren, wurden durch Behandlung mit superkritischem $\mathrm{CO}_{2}$ von einer Dichte größer als $0,73 \mathrm{~g} / \mathrm{mL}$ erhalten. Eine geringere $\mathrm{CO}_{2}$-Dichte führte zu Extrakten mit einem beträchtlichen Anteil von aus dem Tabak stammender Substanzen, es waren jedoch keine Sukroseester nachweisbar. Präparative Superfluid-Chromatographie (SFC) führte $\mathrm{zu}$ einer zusätzlichen Reinigung der mit Sukroseester angereicherten Fraktion nach Optimierung der chromatographischen Säule. Strukturelle Zuweisungen der SFC-Fraktionen wurden durch Gaschromatographie/Massenspektrometrie (GC/MS) in Verbindung mit $\mathrm{N}, \mathrm{O}$-bis(Trimethylsilyl)trifluoroacetamide-Dimethylformamid (BSTFA-DMF) Derivatisierung der freien Hydrolylgruppen sowie Hochdruck-Flüssigkeitschromatographie (HPLC/MS) durchgeführt. Unabhängig von der Tabakart lagen in quantitativer Hinsicht Sukroseester mit einer Acetylgruppe am $\mathrm{C}_{6}$-Atom des Glukosemoleküls (Gruppe III) in höheren Konzentrationen vor als die Sukroseester der Gruppe I (Acetylgruppe am $\mathrm{C}_{3}$-Atom der Fruktose) und die Sukroseester der Gruppe II (Acetylgruppen weder an Glukose noch an Fruktose). Die nachgewiesenen gesättigten Fettsäuren besaßen zwischen maximal18 und mindestens $13 \mathrm{C}$-Atomen. Ungesättigte und isomere Homologe der Fettsäuren wurden in der Gruppe II der Sukroseester nachgewiesen. [Beitr. Tabakforsch. Int. 23 (2008) 32-45]

\section{RESUME}

Les esters de saccharose de tabac oriental mûr ont été isolés, fractionnés et identifiés par des fluides supercritiques. Des extraits riches en esters de saccharose non dérivatisés ont été obtenus par extraction avec un dioxyde de carbone supercritique d'une densité supérieure à $0,73 \mathrm{~g} / \mathrm{mL}$. Des extraits obtenus avec un dioxyde de carbone moins dense sont riches en composants provenant du tabac, avec des teneurs en esters de saccharose non détectables. Une purification supplémentaire de la fraction 


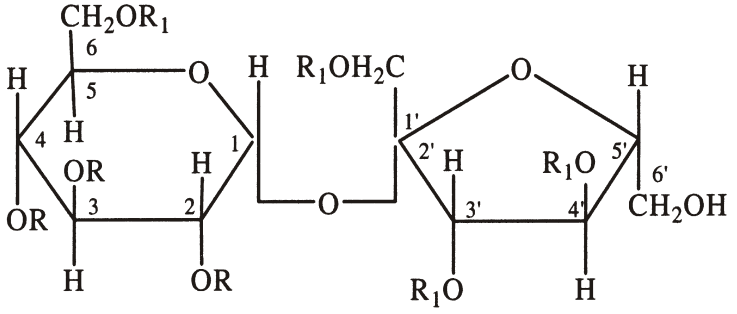

$\mathrm{R}=\mathrm{C}_{3}-\mathrm{C}_{9}$ Acyl groups

$\mathrm{R}_{1}=\mathrm{H}$ or Acetyl

Figure 1. Cuticular sucrose ester types:

A) 6-O-acetyl-2, 3, 4-tri-O-acyl-sucrose - Group III;

B) 6-O-acetyl-2, 3, 4-tri-O-acyl-3'-O-acetyl-sucrose

C 6-O-acetyl-2, 3, 4-tri-O-acyl-4'-O-acetyl-sucrose

D) 2,3,4-tri-O-acyl-sucrose - Group II

E) 2,3,4-tri-O-acyl-3'-acetyl-sucrose - Group I

F) 2,3,4,-tri-O-acyl-4'-O-acetyl-sucrose - Group I

G) 2,3,4-tri-O-acyl-3', 4'-di-O-acetyl-sucrose

H) 2,3,4-tri-O-acyl-1', 3' ,4'-tri-O-acetyl-sucrose

enrichie des esters de saccharose a été obtenue par chromatographie en fluide supercritique (SFC). L'identification structurelle des fractions SFC a été obtenue par chromatographie en phase gazeuse/spectrométrie de masse (GC/MS) accompagnée par dérivatisation des groupes hydroxyles libres par $\mathrm{N}, \mathrm{O}$-bis (triméthylsilyl)-trifluoroacétamidedimethylformamide (BSTFA-DMF) et par chromatographie en phase liquide (HPLC/MS). Du point de vue quantitative indépendamment du type de cigarettes, la teneur en esters de saccharose ayant un groupement acétyle en $\mathrm{C}_{6} \mathrm{du}$ glucose (groupe III) est plus élevée que la teneur en esters de saccharose du groupe I (groupement acétyle en $\mathrm{C}_{3} \mathrm{du}$ fructose) et des esters de saccharose du groupe II (absence du groupement acétyle chez le glucose et le fructose). Des composants d'acides gras saturés disposent de 18 carbones au maximum et de 13 au minimum. Des homologues des acides gras non saturés et isomériques ont été détectés dans les esters de saccharose du groupe II. [Beitr. Tabakforsch. Int. 23 (2008) 34-47]

\section{INTRODUCTION}

Sucrose esters consisting of short chain fatty acids are a major group of tobacco leaf surface chemicals. The first report of a sucrose ester appeared in 1970 with the isolation, structure elucidation, and synthesis of 6-O-acetyl2,3,4-tri- $O$ - $[(+)-3$-methylvaleryl $]-\beta$-D-glucopyranose (1). This and the more predominant sucrose tetra-esters of lower molecular weight carboxylic acids are now considered to be some of the most important aroma precursors responsible for Oriental tobacco flavor (2). These glycolipids also have been shown to have biological activity against insects and plants (3). Nicotiana tabacum species appear to be a fertile source of sucrose esters as well as glucose esters. Plants of 57 Nicotiana species have been screened via thin layer chromatography for glycolipids (4). The results were tentatively classified as follows: a) species having no glycolipids in the surface lipids, b) species having glucose esters mainly, c) species having sucrose esters mainly ( $N$. gluti- nosa, N. tomentosa, N. plumbanginifolia, N. tomentosiformis, $N$. tabacum, and $N$. longiflora), and d) species having both glucose and sucrose esters.

The major sucrose ester from green, field-grown $N$. tabacum tobacco plants has been shown (5) to have an acetate group at the number six carbon of glucose and three other $\mathrm{C}_{3}$ to $\mathrm{C}_{9}$ acyl groups on the 2,3 , and 4 carbons of glucose (e.g. Figure 1, Structure A, Group III). Sucrose esters from green Nicotiana glutinosa have been examined in detail (6). Two gel filtration fractions were analyzed by capillary gas chromatography (GC) after conversion to their trimethylsilyl derivatives. The structure of one fraction contained one acetic acid group esterified to the fructose moiety in addition to three other aliphatic acids on the glucose portion of the sucrose (Figure 1, Structures E and F, Group I). The other fraction only contained three aliphatic acids esterified to hydroxyl groups on the glucose moiety of the sucrose molecule (Figure 1, Structure D, Group II). Sucrose esters isolated from cuticular extracts of other Nicotiana species have been suggested to possess only two $\mathrm{C}_{3}$ to $\mathrm{C}_{8}$ acyl moieties and may have from one to four acetyl groups on the fructose. In summary, about 19 different structural types (Figure 1) of sucrose esters have been reported for Nicotiana species, and for any sugar type, a series of homologs are found due to differing acyl groups (7-14).

Sucrose esters regardless of their structure present real challenges in terms of isolation, sample preparation, and molecular characterization because the materials are partially esterified with linear and branched fatty acids of variable chain length. Within the same molecule the fatty acid residue may also vary in branching, carbon number, and degree of unsaturation. Esterification can be exclusively associated with either glucose or fructose but not necessarily both, thus leading to bipolar structures. Thus, extraction, partitioning, and chromatography may be governed by either the less polar part or the more polar functionality of the sucrose molecule. Up until recently, mass spectral characterization had to be performed on the fully derivatized sucrose ester where complete derivatization and no molecular rearrangement during derivatization were assumed.

Traditionally, isolation of sucrose esters from green tobacco has been via conventional liquid-solid extraction with either methylene chloride (5) or acetonitrile (15) followed by extensive multi-step solvent evaporation and solvent partitioning between either methanol/water, hexane/methanol/water, or chloroform/water. The method employed in many of SEVERSON's (5) papers, Figure 2, concerns first a methylene chloride extraction of the leaf followed by solvent partitioning between hexane and methanol/water then chloroform/water. The chloroform fraction was then subjected to gel filtration twice (LH-20 column) wherein a sucrose ester enriched fraction was achieved. WAGNER and KANDRA (15) later reported acetonitrile extraction, Figure 3 , followed by solvent partitioning between chloroform/water. The chloroform solubles were further fractionated via semi-preparative normal phase high performanceliquid chromatography (HPLC) on a cyano-bonded silica stationary phase with an isooctane/ethanol mobile phase. Three arbitrary fractions were collected with the sucrose esters thought to be generally eluting between 17.5 and 
Green Tobacco

Liquid - Solid Extraction

$\left(\mathrm{CH}_{2} \mathrm{Cl}_{2}\right.$ - Room Temperature - 2X)

$\downarrow$

Solvent Partitioning/Evaporation

(Hexane- $\mathrm{MeOH} / \mathrm{H}_{2} \mathrm{O}(80 / 20)$ - 2X)

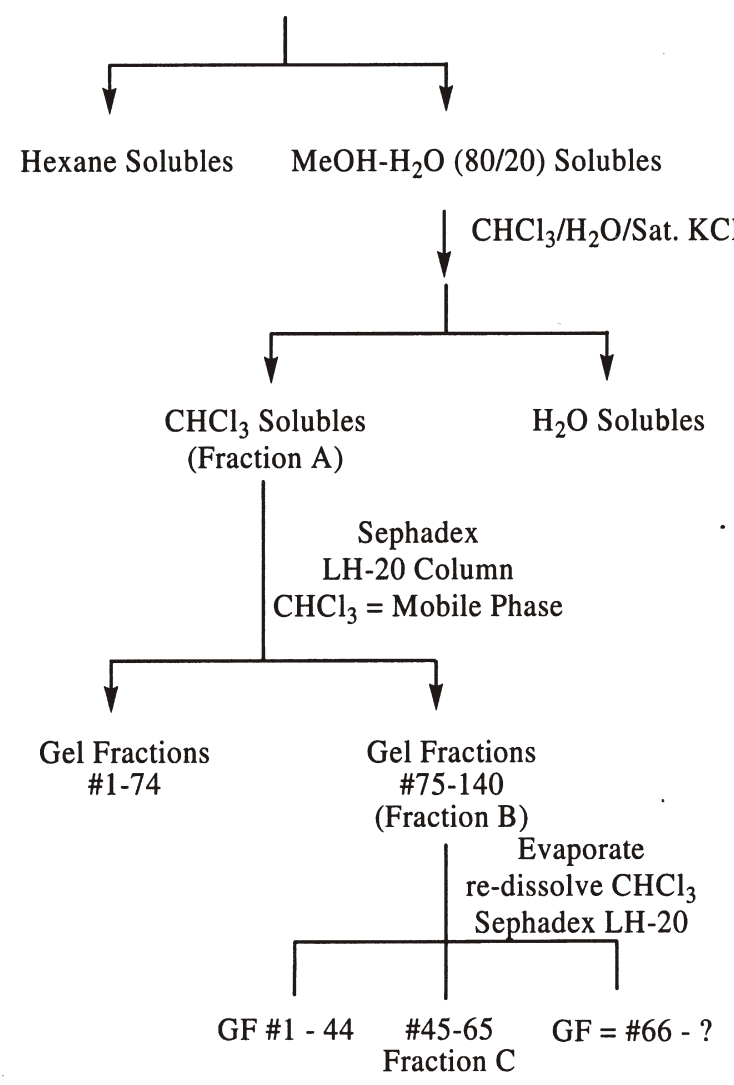

Figure 2. Sample preparation scheme reported by RAY.F. SEVERson et al. (J. Agric. Food Chem. 33 (1985) 870-875)

$30.0 \mathrm{~min}$. For analysis in both cases, the composite fraction had to be derivatized for ultimate gas chromatography/mass spectrometry (GC/MS) examination. Non-sucrose ester impurities were still observed in the fractions of interest in spite of the fact that the procedures were relatively long and tedious. During this timeframe two simpler but apparently less popular isolation methods were reported. One consisted of extraction of the surface of leaf disks with one or two aliquots of methylene chloride followed by selective removal of interfering components using small disposable columns of silica gel (16). GC/MS of the derivatized product constituted the method of analysis. The other method involved soxhlet extraction, addition of an internal standard, then C-18 sep-pak workup followed by direct chemical ionization MS (17).

More recently we have been interested in the nature of sucrose esters derived from five different air-dried aged Oriental tobaccos. Our study differs from previously reported investigations in two respects: a) reversed phase liquid chromatography/electrospray mass spectrometry (RP-HPLC/MS) has been applied to non-derivatized sucrose esters and b) supercritical $\mathrm{CO}_{2}$ has been used to

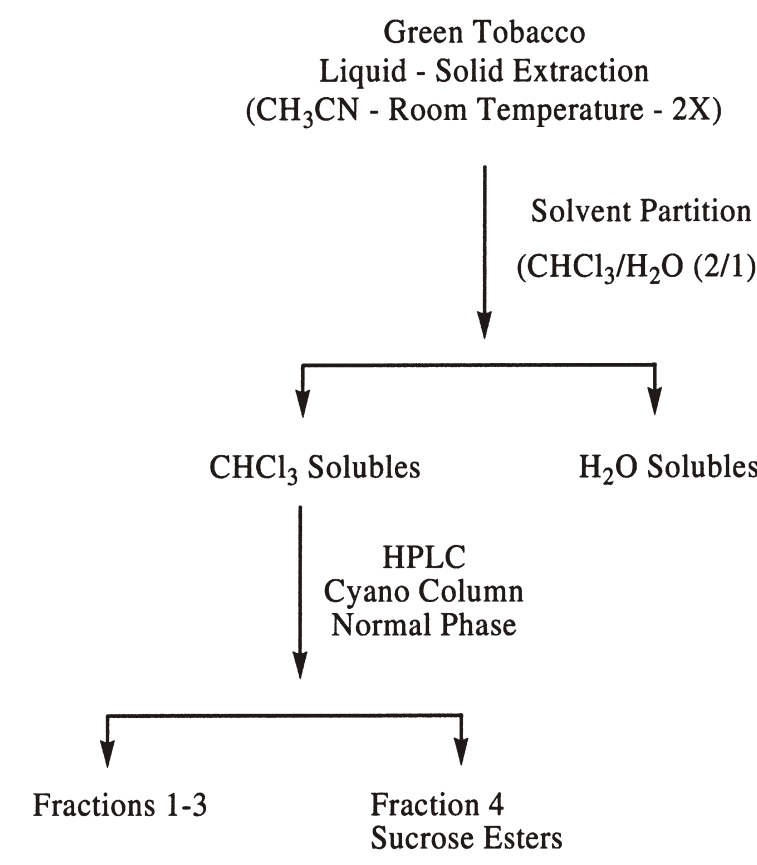

Figure 3. Sample preparation scheme reported by GEORGE J. WAGNER et al. (Biochem. Biophys. 265 (1988) 425-432)

extract the sucrose esters from the ground tobacco. Pure supercritical $\mathrm{CO}_{2}$ at various pressures and temperatures was employed to effect fractionation of tetra-acyl sucrose esters from dried Oriental tobacco without any further pretreatment of the matrix (20). It was determined in this preliminary study that sucrose esters could not be extracted using low density $(0.4-0.7 \mathrm{~g} / \mathrm{mL}) \mathrm{CO}_{2}$, but at this density other analytes which co-extract during the conventional solvent extraction of sucrose esters could be easily removed. At a subsequent higher $\mathrm{CO}_{2}$ density (above $0.73 \mathrm{~g} / \mathrm{mL}$ ), nearly pure sucrose esters could be readily removed with $100 \%$ $\mathrm{CO}_{2}$. Our RP-HPLC/MS study of the crude fractions generated by supercritical fluid extraction followed conventional solvent fractionation using a combination of the Severson and Wagner schemes, Figure 4. RP-HPLC/MS yielded structural information on the types of sucrose esters (i.e. placement of the acetyl group) that were present. In addition to acetyl, the three acyl substitution patterns were governed by the presence of butyl, pentyl, and hexyl substituents. The presence of unsaturation in one of the acyl chains gave rise to another homologous series wherein isomers of the same mass were discovered $(18,19)$.

Our success with supercritical $\mathrm{CO}_{2}$ for extraction has prompted us to now consider supercritical fluid chromatography for isolation of individual sucrose esters that are observed in "crude" extracts as opposed to conventional liquid chromatography. This work was partly motivated by investigations during the mid-1990`s into the composition of cuticular extracts of Nicotiana gossei where workers found sugar fractions incorporating both sucrose and glucose esters (21). The major sucrose esters were reported to be 2,3-di-O-acyl-1'- $O$-acetylsucrose and 2,3-di- $O$-acyl1',6'-di- $O$-acetylsucrose which yet constitute another type of sucrose ester not mentioned in Figure 1. The predominant acid moieties were 5-methylhexanoic and 5-methyheptanoic acids. 


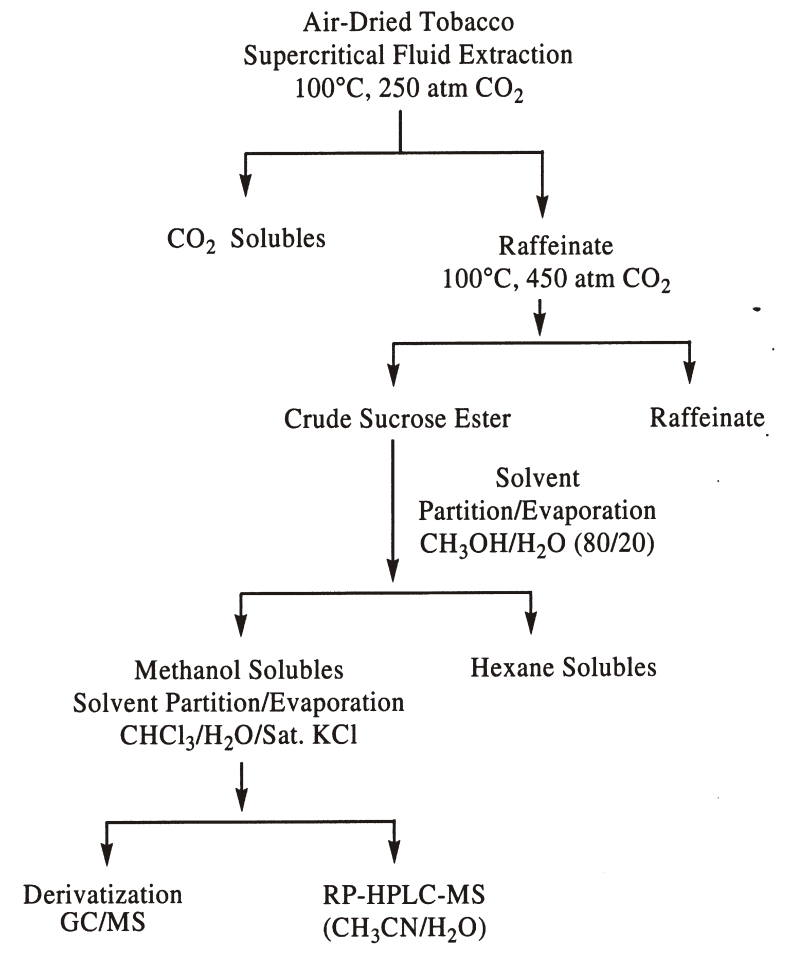

Figure 4. Sample preparation scheme reported by MEHDI Ashraf-KHORASSANI et al. (J. Agric. Food Chem. 53 (2005) 1866-1872)

We now wish to report our results concerning the characterization of sucrose esters derived from five Oriental tobacco samples employing first supercritical fluid extraction to produce the crude sucrose ester extract and then a combination of supercritical fluid-gas-liquid chromatographies coupled with evaporative light scattering and mass spectral detection applied to the crude extract. Air-dried, ground Oriental tobacco samples [from a previous classical liquid phase study (19) with conventional solvents] served as the source of sucrose esters.

\section{EXPERIMENTAL}

\section{Chemicals}

Air-dried ground Oriental tobacco samples were obtained from R.J. Reynolds Tobacco Co. (Winston Salem, NC USA). Solvents were obtained from EM Science (Gibbstown, NJ USA) as HPLC grade, and each was used as received. All other chemicals were obtained from SigmaAldrich (St. Louis, MO USA).

\section{Extraction of sucrose esters}

Sucrose ester-enriched extracts were obtained using an IscoSuprex (Lincoln, NE USA) AP-44 Supercritical Fluid Extraction (SFE) system. A previously described method(20) was used for all the extractions. In this method, 2 grams of dry tobacco were transferred to a $10 \mathrm{~mL}$ stainless steel vessel which was pressurized at $100{ }^{\circ} \mathrm{C}$ using pure $\mathrm{CO}_{2}(250 \mathrm{~atm})$. The extraction was performed dynamically at a flow rate of $2 \mathrm{~mL} / \mathrm{min}$ for $120 \mathrm{~min}$. Since this extract was believed to not contain sucrose ester, it was set aside. Extraction of the sample was continued by subjecting the raffeinate to higher $\mathrm{CO}_{2}$ pressure $(450 \mathrm{~atm})$ again at $100{ }^{\circ} \mathrm{C}$ and $2 \mathrm{~mL} / \mathrm{min}$ for an additional $120 \mathrm{~min}$ in order to preferentially remove sucrose ester analytes. This second extract was further fractionated via preparative supercritical fluid chromatography (SFC) as described below.

\section{Preparative supercritical fluid chromatography}

All SFC separations were obtained using a Mettler-Toledo (Newark, DE USA) Minigram Berger SFC system capable of both analytical and semi-preparative scale separations. Bare silica in addition to various bonded phase, silica-based, analytical scale columns such as Cyano and Diol from MettlerToledo, Amino from Keystone Scientific Co. (Bellefonte, PA USA), and Octadecyl from Phenomonex (Torrance, CA USA) were first tested to determine which stationary phase provided the best separation. In the final analysis, collection of two discrete fractions of sucrose esters was accomplished using a semi-preparative Diol column $\left(250 \times 10 \mathrm{~mm}, 5 \mu \mathrm{m} \mathrm{d}_{\mathrm{p}}\right.$, Mettler-Toledo). Detection during fractionation of sucrose esters on both analytical and preparative scale separations was achieved using an Alltech (Deerfield, IL USA) evaporative light scattering detector (ELSD). The following chromatographic conditions were employed to obtain a successful analytical scale separation of sucrose esters:

$\mathrm{CO}_{2}$ pressure: $120 \mathrm{~atm}$; oven temperature: $70^{\circ} \mathrm{C}$; flow rate: $3 \mathrm{~mL} / \mathrm{min}$; injection volume: $20-40 \mu \mathrm{L}$; modifier: methanol; modifier gradient: initial $90 / 10 \mathrm{CO}_{2} / \mathrm{MeOH}$ hold for 3 min, ramp to $65 / 35 \% \mathrm{CO}_{2} / \mathrm{MeOH}$ at $2 \% / \mathrm{min}$, hold for additional $5 \mathrm{~min}$.

For light scattering detection, only $0.5 \mathrm{~mL} / \mathrm{min}$ of the total column flow of liquid $\mathrm{CO}_{2}$ was transferred to the detector. The remaining effluent was collected in various tubes for further analysis via HPLC/MS and GC/MS. The residual methanol in each isolated fraction was evaporated to dryness using $\mathrm{N}_{2}$, after which the samples were re-dissolved in $2 \mathrm{~mL}$ of $\mathrm{MeOH}$.

\section{Gas chromatography-mass spectrometry analysis}

After completion of SFC fractionation and re-dissolution of the collected samples, $0.2 \mathrm{~mL}$ of each $\mathrm{MeOH}$ solution was quantitatively transferred into a $\mathrm{GC}$ vial for derivatization. First, the methanol was evaporated to dryness aided by $\mathrm{N}_{2}$ at room temperature. $\mathrm{N}, \mathrm{O}$-bis(trimethylsilyl)trifluoroacetamide - dimethylformamide (BSTFA-DMF) $(1: 1,250 \mu \mathrm{L}$ ) was then added to each vial for the purpose of forming trimethylsilyl ethers of the unacetylated hydroxyl groups on each sucrose ester molecule. Each vial was purged with $\mathrm{N}_{2}$, secured with a Teflon-lined cap and heated for $30 \mathrm{~min}$ at $70{ }^{\circ} \mathrm{C}$. After cooling, the samples were placed inside a 7673 Agilent autosampler for subsequent GC analysis. Analyses were performed using an Agilent 5890 gas chromatograph (Wilmington, DE USA) equipped with a 5972 mass selective detector (MSD). GC separations were performed with a DB5 MS capillary column $\left(15 \mathrm{~m} \times 0.25 \mathrm{~mm}\right.$ i.d., $0.25 \mu \mathrm{m} \mathrm{d}_{\mathrm{f}}, \mathrm{J}$ $\&$ W Scientific, Folsom, CA USA). All GC runs were carried out using the following temperature program: Initial $80{ }^{\circ} \mathrm{C}$, hold for $2 \mathrm{~min}$, ramp to $140^{\circ} \mathrm{C}$ at $10^{\circ} \mathrm{C} / \mathrm{min}$ and then ramp to $290{ }^{\circ} \mathrm{C}$ at $4{ }^{\circ} \mathrm{C} / \mathrm{min}$, hold at $290{ }^{\circ} \mathrm{C}$ for $10 \mathrm{~min}$. 


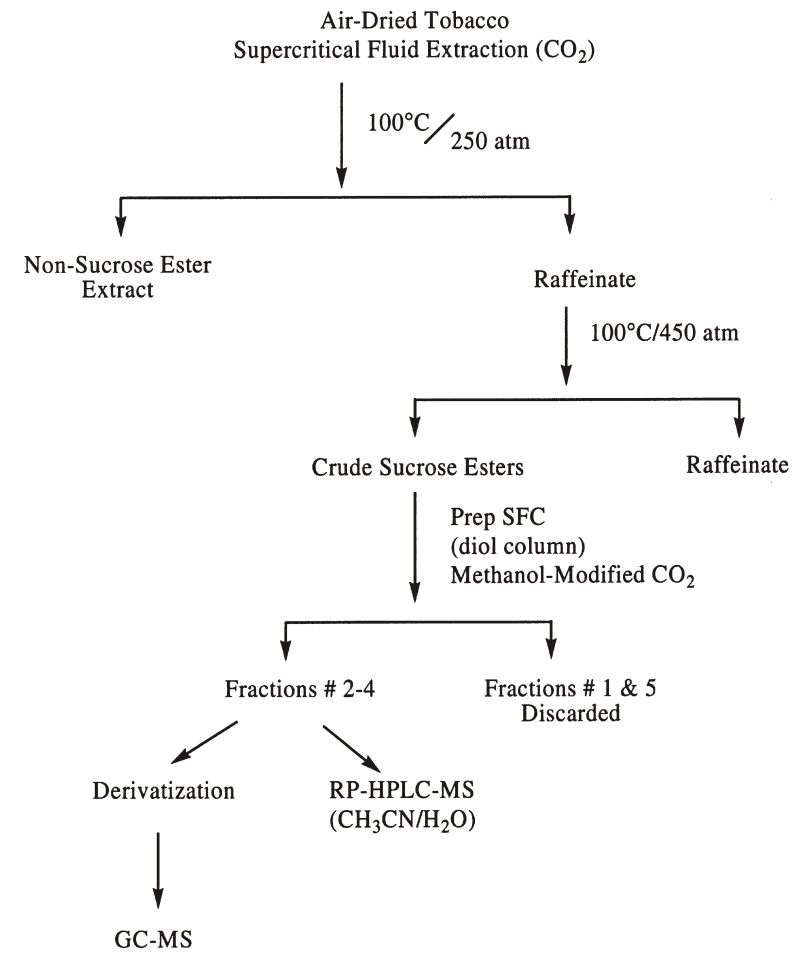

Figure 5. Sample preparation scheme reported in this manuscript.

\section{High performance-liquid chromatography/mass spectrometry analysis}

All HPLC separations were obtained on non-derivatized sucrose esters using an Agilent (Wilmington, DE USA) HPLC 1100 series equipped with diode array detector, column heater, and Thermo Survey (San Jose, CA USA) auto-sampler. A methanol solution $(10 \mu \mathrm{L})$ of each sucrose ester fraction was then injected onto the column via the auto-sampler. The column for all HPLC separations was a Phenomonex (Torrance, CA USA) silica based- $\mathrm{C}_{18}(150 \times$ $\left.2.1 \mathrm{~mm}, 5 \mu \mathrm{m}, \mathrm{d}_{\mathrm{p}}\right)$. Mobile phase A consisted of $1 \%$ aqueous formic acid; while mobile phase B contained 1\% $(\mathrm{v} / \mathrm{v})$ formic acid in acetonitrile. The mobile phase was delivered to the HPLC column at a flow rate of $0.2 \mathrm{~mL} / \mathrm{min}$ and the gradient mobile phase elution program was as follows: $0-3 \mathrm{~min}: 100 \% \mathrm{~A} ; 45 \mathrm{~min}: 100 \% \mathrm{~B} ; 55 \mathrm{~min}: 100 \%$ B; 60 min: $100 \%$ A; 5 min post run).

For mass spectral analysis, the HPLC column effluent was pumped directly (without split) into the spray chamber of a Thermo Instrument TSQ triple quadrupole mass spectrometer (Thermo Finnigan, San Jose, CA USA) equipped with an ESI source. The instrument was calibrated with a solution of polytyrosine according to the manufacturer's recommendation. Tuning parameters were established via trial and error in order to achieve reasonable MS sensitivity and analyte identification information. MS parameters for separation and detection of the underivatized sucrose esters are listed below:

Spray voltage: $3200 \mathrm{~V}$; sheath gas pressure: 49 arbitrary values; auxiliary gas pressure: 13 arbitrary values; capillary temperature: $300{ }^{\circ} \mathrm{C}$.

\section{RESULTS AND DISCUSSION}

The objectives of this study were fourfold: a) establish the feasibility of supercritical fluid chromatography for separating underivatized crude extracts of sucrose esters, a) identify on-line (after SFC) specific underivatized sucrose esters via RP-LC/MS, (3) characterize preparative SFC fractions via high resolution GC/MS after appropriate derivatization, and (4) compare results with previously reported data which were obtained using normal phase HPLC of crude sucrose ester extracts followed by RPHPLC/MS of the normal phase isolated fractions. Our experimental strategy is outlined in Figure 5.

\section{Supercritical fluid chromatography}

In order to determine which stationary phase was best suited for SFC of the crude sucrose ester supercritical $\mathrm{CO}_{2}$ extracts, various stationary phases were tested. Initially, we assumed that since sucrose esters could be extracted from tobacco with $100 \% \mathrm{CO}_{2}$, chromatographic separation of sucrose esters from a packed column could be achieved with the same pure fluid. Unfortunately, this assumption was not realized. Apparently the tobacco matrix was less active or there were tobacco co-extractives which aided in the removal of sucrose esters from tobacco with pure $\mathrm{CO}_{2}$. The chromatographic traces that were obtained with various single analytical scale columns that differ in stationary phase are shown in Figure 6. In each case, methanol modifier was required in order to achieve elution of the previously extracted sucrose esters. Our results showed that the diol phase provided slightly more resolved components compared to the other tested columns. One of the advantages of SFC is the ability to stack several columns of the same or differing selectivity to enhance efficiency. However, combination of a $25 \mathrm{~cm}$ diol and $25 \mathrm{~cm}$ cyano phase afforded little improvement in separation. The great similarity of all sucrose esters no doubt contributed to the less than ideal resolution. Six diol stacked columns (i.e. 150 $\mathrm{cm}$ ) yielded 3-4 separable regions which suggested the presence of groups of esters rather than individual esters. Due to the low UV absorptivity of sucrose esters, an evaporative light scattering detector was employed for these separations. For preparative, fractionation purposes, however, a single larger $\left(250 \times 10 \mathrm{~mm}, 5 \mu \mathrm{m} \mathrm{d}_{\mathrm{p}}\right)$ diol semiprep column seemed to suffice. The evaporative light scattering detector (ELSD) trace obtained with the semiprep column and the assignment of five arbitrarily chosen fractions are shown in Figure 7.

\section{Gas chromatography/mass spectrometry}

The free hydroxyl groups of an aliquot from each of the five isolated chromatographic fractions were derivatized via BSTFA-DMF, and the resulting product was analyzed via GC. Peaks eluting at 35-40 min, Figure 8, are believed to be due to trimethylsilyl ether derivatives of sucrose esters based on analyses of the mass spectra from this region of the chromatography. A complicated envelope of chromatographic peaks also appeared at 20-30 min but these compo- 

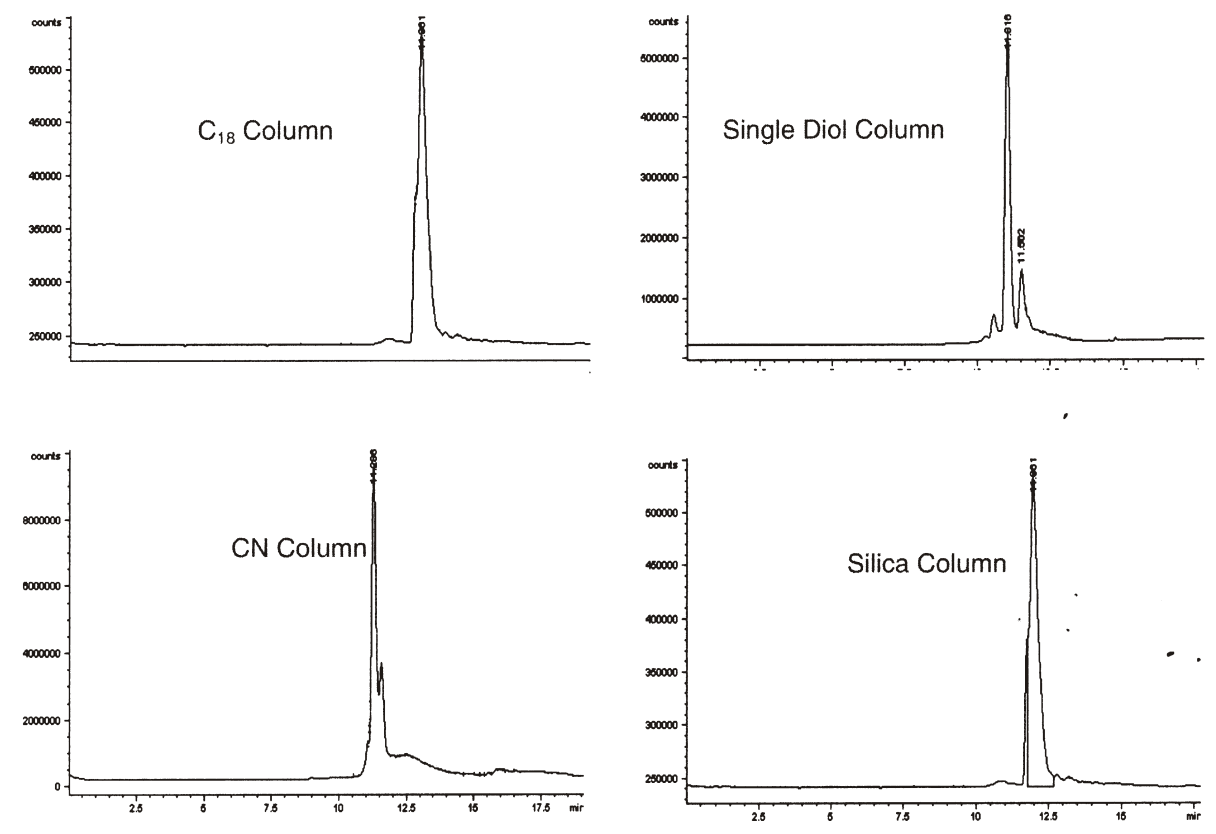

Figure 6. Analytical SFC Separation of Sucrose Ester using Selected Single Analytical Scale Columns of Different Phases (see Experimental section for chromatography conditions)

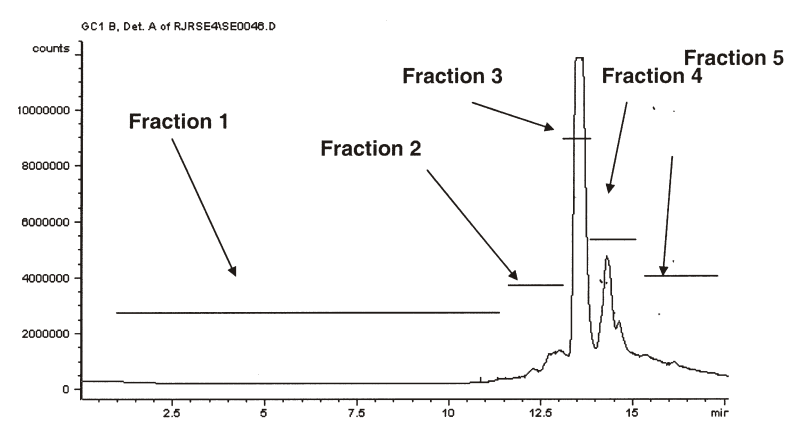

Figure 7. SFC/ELSD trace of semi-prep column for separation of sucrose ester extract using diol column $\left(250 \times 10 \mathrm{~mm}, 5 \mu \mathrm{m} d_{p}\right)$

nents were not related to sucrose esters. As can be observed, most of the sucrose esters were observed in SFC fractions no. 3 and no. 4 . We feel that the sucrose esters in fraction no. 2 are the result of cross contamination from fraction no. 3. The other two fractions (no. 1 and no. 5) were almost totally void of any sucrose ester. It appeared from both SFC/ELSD and GC/MS traces that the concentration of sucrose esters in fraction no. 4 was much lower than in fraction no. 3. An expanded view of the GC/MS trace of both derivatized fractions suggested the presence of a large number of unique sub-groups within each fraction, Figure 9. Thus, the large peak observed in the SFC trace, Figure 7, represented response from the majority of the sucrose esters.

For discussion purposes in this report, it has been generally reported that the majority of sucrose esters are best grouped into three general structures even though additional groups have been suggested to be present in sucrose esters derived from tobacco products. The three classical Groups (Figure 1) can be distinguished from each other by the relative location of the lone acetyl ester function. Group I has the lone acetyl group attached to carbon-3 of fructose, Group II has no acetyl group on either glucose or fructose, and Group III has the acetyl group attached to the carbon-6 oxygen of glucose. Based on the MS spectra of GC separated compounds, it was determined that SFC fraction no. 3 contained mostly Group III and maybe a small amount of Group I sucrose esters (Figure 10). While the GC/MS spectra of peak components originating from SFC fraction no. 4 (Figure 11) showed predominantly Group II type sucrose esters.

If one looks at the individual mass spectra of GC peaks arising from fraction no. 3 (Figure 10), the highest glucose mass that can be observed is $m / z 499$ which means that the glucose contains an acetyl group and the three fatty acid constituents are $\mathrm{C}_{7}, \mathrm{C}_{6}, \mathrm{C}_{5}$ or $\mathrm{C}_{6}, \mathrm{C}_{6}, \mathrm{C}_{6}$. The fructose part of the molecule has $\mathrm{m} / \mathrm{z} 451$ which corresponds, as expected, to fructose with four trimethylsilyl ether groups and a fragment with $\mathrm{m} / \mathrm{z} 361$ assignable to fructose with three silyl ethers. Next, we looked at the on-line mass spectra of peaks coming from SFC fraction no. 4 (Figure 11). The sucrose esters in Group II do not have an acetyl moiety on either glucose or fructose. The 4 hydroxyl groups on fructose should be fully derivatized to yield both $\mathrm{m} / \mathrm{z}$ 451 and $\mathrm{m} / \mathrm{z} 361$ as described above for Group III. Both of these fragments can be observed in most mass spectra arising from GC/MS analysis of SFC fraction no. 4. The glucose part of these sucrose esters in this fraction has three acyl groups and one hydroxyl group. During the derivatization process, this lone hydroxyl group should have been converted to a trimethyl silyl (TMS) ether functionality. Therefore, the $\mathrm{m} / \mathrm{z}$ of the glucose part with, for example, the three $R$ groups equal to $\mathrm{C}_{7}, \mathrm{C}_{6}, \mathrm{C}_{5}$ and one trimethyl silyl (TMS) group will total 529. This fragment can be observed in the mass spectrum (GC/MS) of a SFC 

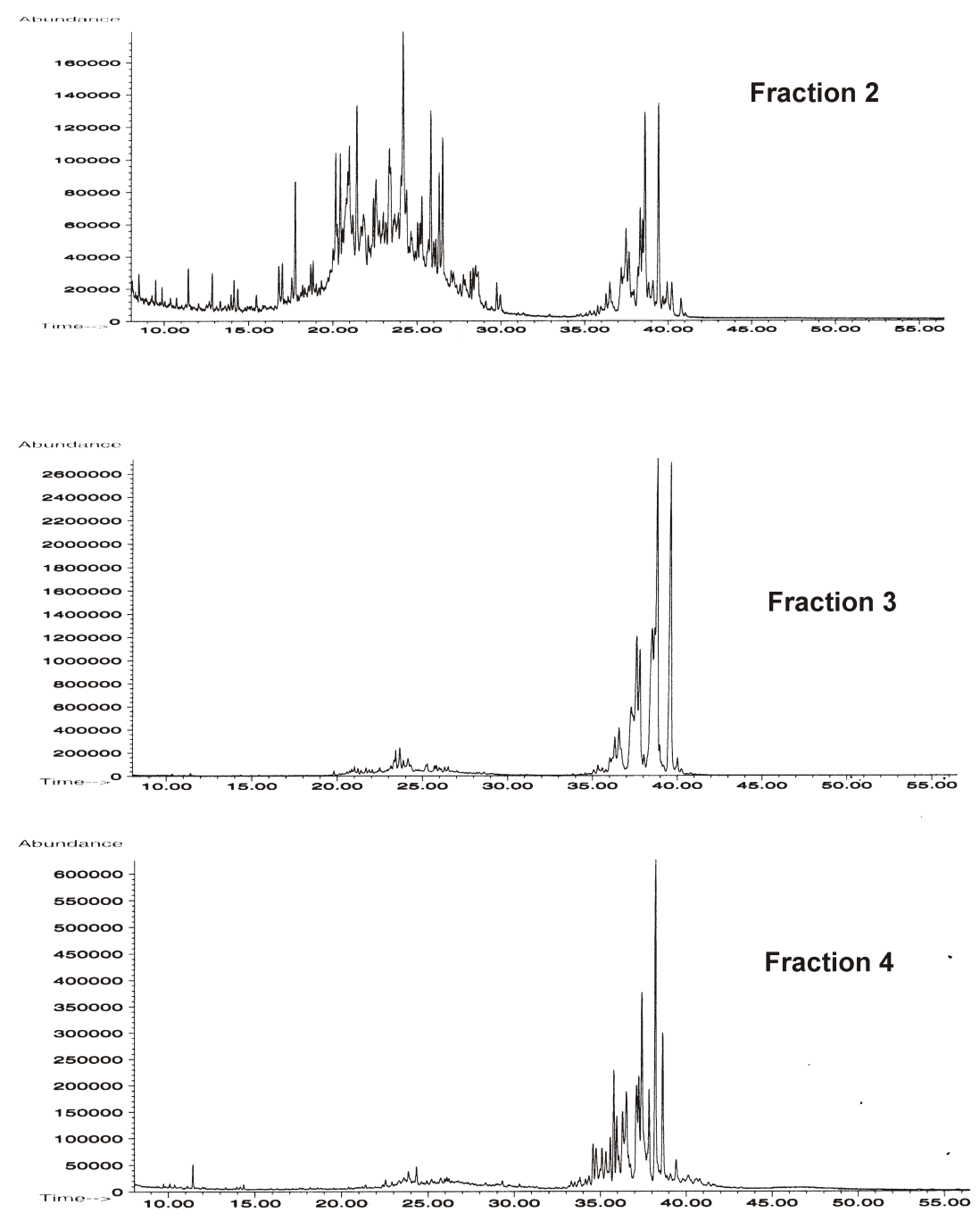

Figure 8. GC/MS of three (out of five) collected SFC fractions that exhibited the presence of sucrose esters


Figure 9. An expanded view of the GC/MS trace of both derivatized SFC fractions no. 3 (A) and no. 4 (B) 


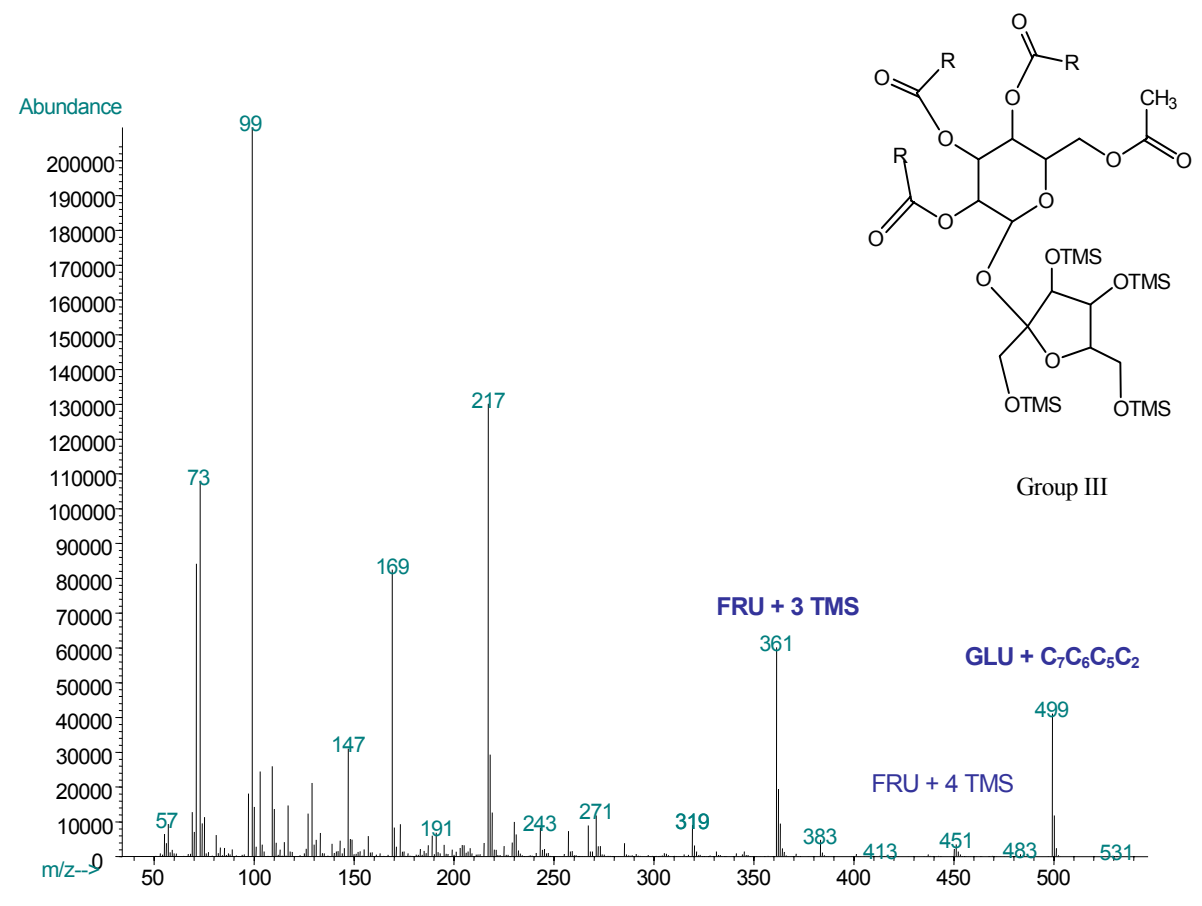

Figure 10. Mass spectrum of GC peak arising from SFC fraction no. 3

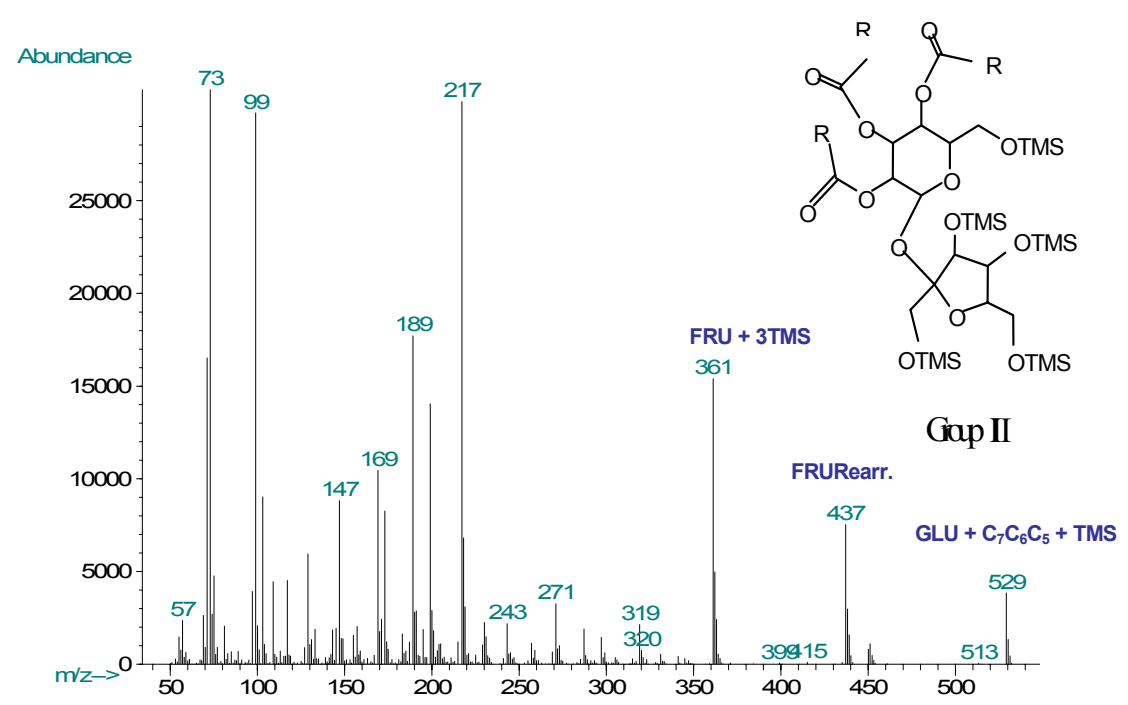

Figure 11. Mass spectrum of GC peak arising from SFC fraction no. 4

fraction no. 4 peak with retention time $38.64 \mathrm{~min}$. Similar observations for other SFC fraction no. 4 peaks with shorter retention times were apparent. The $\mathrm{m} / \mathrm{z}$ attributable to the glucose portion of the molecule decreased by 14 as the retention time decreased. In summary, it was concluded from the GC/MS examination of derivatized sucrose esters that fraction no. 3 was mostly Group III; while fraction no. 4 contained only Group II sucrose esters. Assignments such as these should be viewed with some caution as the esters have been derivatized prior to spectral analysis.
Since there exist numerous hydroxyl functionalities on each molecular unit and complete derivatization may be less than $100 \%$, interpretation should be performed with caution.

\section{Reversed phase liquid chromatography/} mass spectrometry

In order to be more definitive concerning our GC/MS assignments based on derivatized material, the third and 

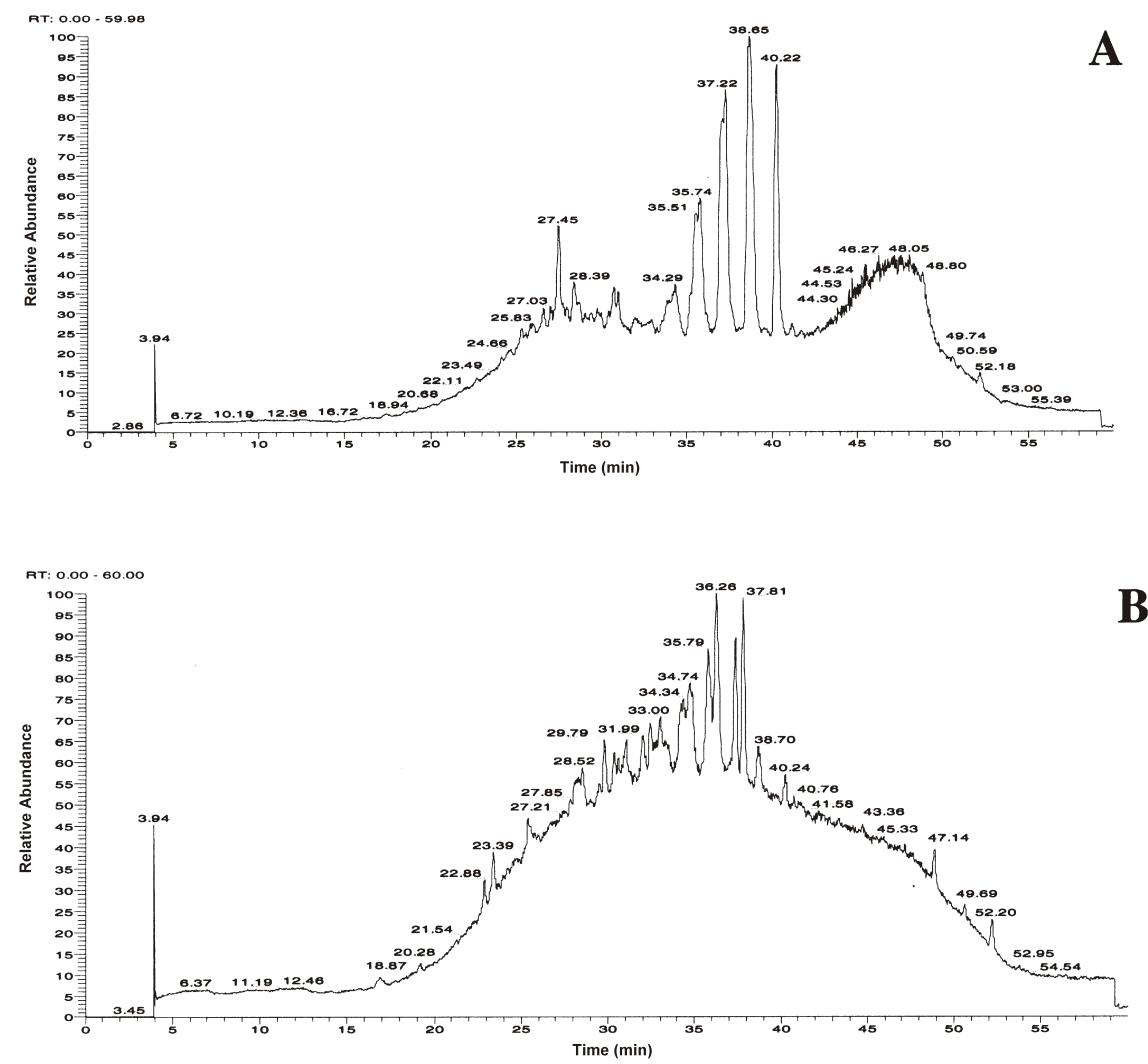

Figure 12. RP-HPLC/MS total ion chromatograms (TIC) of SFC fractions no. 3 (A) and no. 4 (B)

Table 1. Predicted mono-isotopic mass data (MM) for Groups I, II, and III sucrose ester homologs

\begin{tabular}{|c|c|c|c|c|c|c|c|}
\hline \multirow[b]{2}{*}{$\left(\mathrm{MM}+\mathrm{NH}_{4}\right)^{+}$Adduct } & \multirow[b]{2}{*}{ MM Parent } & \multicolumn{2}{|c|}{ Group I } & \multicolumn{2}{|c|}{ Group II } & \multicolumn{2}{|c|}{ Group III } \\
\hline & & $\begin{array}{c}\text { GLU-OAc }^{a} \\
\text { Fragment }\end{array}$ & $\begin{array}{l}\mathrm{FRU}+O A c^{a} \\
\text { Fragment }\end{array}$ & $\begin{array}{l}\text { GLU-OAC } \\
\text { Fragment } \\
\end{array}$ & $\begin{array}{l}\text { FRU-OAc } \\
\text { Fragment }\end{array}$ & $\begin{array}{c}\text { GLU+OAc } \\
\text { Fragment } \\
\end{array}$ & $\begin{array}{l}\text { FRU-OAc } \\
\text { Fragment }\end{array}$ \\
\hline 584 & 566 & $345(10 C)$ & $205(2 C)$ & $387(13 C)$ & 163 (ZeroC) & $387(13 C)$ & 163 \\
\hline 598 & 580 & $359(11 \mathrm{C})$ & $205(2 C)$ & $401(14 C)$ & 163 (ZeroC) & $401(14 C)$ & 163 \\
\hline 612 & 594 & $373(12 \mathrm{C})$ & $205(2 C)$ & $415(15 \mathrm{C})$ & 163 (ZeroC) & $415(15 \mathrm{C})$ & 163 \\
\hline 626 & 608 & $387(13 C)$ & $205(2 C)$ & $429(16 C)$ & 163 (ZeroC) & $429(16 C)$ & 163 \\
\hline 640 & 622 & $401(14 C)$ & $205(2 C)$ & $443(17 \mathrm{C})$ & 163 (ZeroC) & $443(17 \mathrm{C})$ & 163 \\
\hline 654 & 636 & $415(15 \mathrm{C})$ & $205(2 C)$ & $457(18 C)$ & 163 (ZeroC) & $457(18 C)$ & 163 \\
\hline 668 & 650 & $429(16 C)$ & $205(2 C)$ & $471(19 C)$ & 163 (ZeroC) & $471(19 C)$ & 163 \\
\hline 682 & 664 & $443(17 C)$ & $205(2 C)$ & $485(20 C)$ & 163 (ZeroC) & $485(20 C)$ & 163 \\
\hline 696 & 678 & $457(18 C)$ & $205(2 C)$ & $499(21 C)$ & 163 (ZeroC) & $499(21 C)$ & 163 \\
\hline 710 & 692 & $471(19 C)$ & $205(2 C)$ & & & $513(22 \mathrm{C})$ & 163 \\
\hline 724 & 706 & $485(20 C)$ & $205(2 C)$ & & & $527(23 C)$ & 163 \\
\hline 738 & 720 & $499(21 C)$ & $205(2 C)$ & & & $541(24 C)$ & 163 \\
\hline 752 & 734 & $513(22 \mathrm{C})$ & $205(2 C)$ & & & $555(25 C)$ & 163 \\
\hline
\end{tabular}

${ }^{\text {a }}$ Glucose + fructose fragments $+16=$ molecular mass of the parent.

fourth SFC fractions were analyzed again via RPHPLC/MS in the electrospray ionization mode, but this time the study was done without prior derivatization of the components. Figure 12 shows the total ion current chromatograms (TIC) of both fractions. The pertinent, predicted mono-isotopic molecular mass data of what we believe to be a) each major sucrose ester component (e.g. Groups I, II, and III), b) the associated ammonium ion adduct, and c) various possible glucose and fructose fragments derived therefrom for 13 homologs are listed in Table 1. At the outset of this work, the approach with underivatized analyte was thought to possibly yield a more straightforward interpretation of the data than GC/MS of derivatized components. A series of homologs that differ by $14 \mathrm{amu}$ with the acetyl group either attached to glucose (Group III) or fructose (Group I) or the acetyl group not attached at all 
Table 2. Chromatographic and mass spectral data (MM) for observed Group III homologs via RP-HPLC/MS: SFC fraction no. 3 different Oriental tobaccos

\begin{tabular}{|c|c|c|c|c|c|c|c|c|c|c|c|c|c|}
\hline \multirow[b]{2}{*}{$\begin{array}{l}\left(\mathrm{MM}+\mathrm{NH}_{4}\right)^{+} \\
\text {Adduct }\end{array}$} & \multirow[b]{2}{*}{$\begin{array}{c}\text { MM } \\
\text { Parent }\end{array}$} & \multirow[b]{2}{*}{$\begin{array}{c}\text { GLU + } \\
\text { OAc }\end{array}$} & \multicolumn{3}{|c|}{ Sample 1} & \multicolumn{3}{|c|}{ Sample 2} & \multicolumn{2}{|c|}{ Sample 3} & \multicolumn{2}{|c|}{ Sample 4} & \multirow{2}{*}{$\begin{array}{c}\text { Sample } 5 \\
t_{\mathrm{r}}, \min \\
\mathrm{PK} 1\end{array}$} \\
\hline & & & $\begin{array}{l}t_{\mathrm{r}}, \min \\
\mathrm{PK} 1\end{array}$ & \begin{tabular}{|c|}
$t_{\mathrm{r}}, \min$ \\
$\mathrm{PK} 2$ \\
\end{tabular} & $\begin{array}{c}t_{R}, \min \\
\text { PK } 3\end{array}$ & $\begin{array}{l}t_{\mathrm{r}}, \min \\
\mathrm{PK} 1 \\
\end{array}$ & $\begin{array}{l}t_{\mathrm{r}}, \min \\
\mathrm{PK} 2 \\
\end{array}$ & $\begin{array}{l}t_{\mathrm{r}}, \min \\
\mathrm{PK} 3 \\
\end{array}$ & $\begin{array}{l}t_{\mathrm{r}}, \min \\
\mathrm{PK} 1\end{array}$ & $\begin{array}{l}t_{\mathrm{r}}, \min \\
\mathrm{PK} 2 \\
\end{array}$ & $\begin{array}{l}t_{\mathrm{r}}, \min \\
\mathrm{PK} 1\end{array}$ & $\begin{array}{l}t_{\mathrm{r}}, \min \\
\mathrm{PK} 2\end{array}$ & \\
\hline 598 & 580 & 401 & 29.72 & & & 29.75 & 31.97 & 32.42 & 29.74 & 32.44 & 29.77 & 32.44 & 32.42 \\
\hline 612 & 594 & 415 & 31.41 & & & 31.41 & 33.38 & & 31.48 & 33.38 & 31.48 & & 31.50 \\
\hline 626 & 608 & 429 & 32.72 & 34.71 & & 32.77 & 34.86 & & 32.79 & 34.81 & 32.79 & & 32.77 \\
\hline 640 & 622 & 443 & 33.94 & 34.27 & 36.26 & 33.92 & 34.34 & 36.24 & 34.34 & & 34.36 & & 34.34 \\
\hline 654 & 636 & 457 & 35.72 & & & 35.77 & 37.81 & & 35.79 & & 35.88 & & 35.84 \\
\hline 668 & 650 & 471 & 37.22 & & & 37.15 & & & 37.27 & & 37.29 & & 37.24 \\
\hline 682 & 664 & 485 & 38.84 & & & 38.45 & 38.91 & & 38.72 & & 38.69 & & 38.67 \\
\hline 696 & 678 & 499 & - & & & 40.39 & & & 40.31 & & 40.40 & & 40.26 \\
\hline 710 & 692 & 513 & 41.72 & & & 41.74 & & & 41.76 & & 41.79 & & 41.81 \\
\hline
\end{tabular}

Table 3. Chromatographic and mass spectral data (MM) for observed Group I homologs via RP-HPLC/MS: SFC fraction no. 3 different Oriental tobaccos

\begin{tabular}{lc|c|c|c|c|c|c|c}
\hline$\left(\mathrm{MM}+\mathrm{NH}_{4}\right)^{+}$Adduct & MM Parent & $\begin{array}{c}\text { GLU-OAc }^{\mathrm{a}} \\
\text { Fragment }\end{array}$ & $\begin{array}{c}\text { FRU+OAc } \\
\text { Fragment }\end{array}$ & $\begin{array}{c}\text { Sample 1 } \\
t_{\mathrm{r}}, \mathrm{min}\end{array}$ & $\begin{array}{c}\text { Sample 2 } \\
t_{\mathrm{r}}, \mathrm{min}\end{array}$ & $\begin{array}{c}\text { Sample 3 } \\
t_{\mathrm{r}}, \mathrm{min}\end{array}$ & $\begin{array}{c}\text { Sample 4 } \\
t_{\mathrm{r}}, \mathrm{min}\end{array}$ & $\begin{array}{c}\text { Sample 5 } \\
t_{\mathrm{r}}, \mathrm{min}\end{array}$ \\
\hline 626 & 608 & 387 & 205 & 30.52 & 30.50 & 30.68 & 30.66 & 30.71 \\
640 & 622 & 401 & 205 & 32.18 & 32.18 & 32.21 & 32.23 & - \\
682 & 664 & 443 & 205 & 33.52 & 3357 & - & 38.85 & 38.13 \\
696 & 678 & 457 & 205 & 37.97 & 38.18 & 39.63 & 39.58 & 39.70 \\
710 & 692 & 471 & 205 & 39.75 & 39.68 & 39.70 & 39.82 & 39.84 \\
724 & 706 & 485 & 205 & 41.20 & 41.21 & 41.23 & 41.30 & 41.29 \\
738 & 720 & 499 & 205 & 42.66 & 42.66 & 42.72 & 42.75 & 42.74 \\
\hline
\end{tabular}

${ }^{\text {a }}$ Glucose + fructose fragments $+16=$ molecular mass of parent.

(Group II) was expected. If the acetyl is attached to glucose, the corresponding fragment masses can be found in Table 1 under GLU+OAc and FRU-OAc and if acetyl is attached to fructose, the corresponding masses can be found under GLU-OAc and FRU+OAc and if the molecule does not contain the acetyl group, the corresponding masses can be found under GLU-OAc and FRU-OAc. This approach, however, we discovered has a pitfall in that one acetyl group has a mass of 43 . Replacement of an hydroxyl hydrogen with the acetyl moiety corresponds to a net gain in mass of 42 which just happens to equal the molecular mass of three methylene units. In other words, employing mass spectrometry alone, a fatty acid group with an additional three methylene groups could easily be mistaken or misinterpreted for an acetyl group.

The data concerning the first series of experimentally detected molecules via RP-HPLC/MS analysis of SFC fraction no. 3 (e.g. Group III) for each of five different Oriental tobaccos in the extracted ion mode are shown in Table 2. The experimentally measured sucrose ester $\mathrm{m} / \mathrm{z}$ value for each parent, its $\mathrm{NH}_{4}^{+}$adduct, its glucose fragment which incorporates the acetyl group, and the retention time of any eluted peaks which match the mass data are tabulated. As can be observed, the lowest parent sucrose ester $\mathrm{m} / \mathrm{z}$ in which acetyl is attached to glucose was detected at 580, and the highest $\mathrm{m} / \mathrm{z}$ was found at 692 , for a total of nine homologs. The presence of multiple peaks for several of the masses suggested that isomers of Group III sucrose esters exist. The fact that certain
Oriental tobaccos (i.e. sample no. 2) appeared to exhibit more isomerism than others is significant. Coupling this observation with the fact that the extracted sucrose ester concentration varied considerably from one tobacco to another would suggest a wide array of sensory attributes across these tobaccos. Without hydrolysis of the sucrose ester coupled with GC of the released fatty acid, we are unable to identify the nature of the isomerism for a fixed molecular mass. However, the analysis of mainstream particulate phase of cigarette smoke reveals the presence of significant amounts of relatively low molecular weight carboxylic acids possessing branched acyl side chains. Most notable among these acids was 3-methyl pentanoic, 3-methyl butanoic, and 2-methyl propanoic acids (22, 23). Branched chain carboxylic acids have also been detected in other Nicotiana species (21). Thus, the isomerization noted in these Oriental tobacco samples, particularly sample no. 2, can most likely be attributed to $\mathrm{C}_{6}, \mathrm{C}_{5}$, and $\mathrm{C}_{4}$ alkyl chains having branch points along the chain. Further analysis of the same SFC fraction no. 3 revealed a second series of peaks which are believed to be Group I (lone acetyl group on carbon-3 of fructose) sucrose esters. The presence of these Group I esters was suspected from the GC/MS data, vide supra, but their proof was not conclusive. The anticipated mono-isotopic mass of each parent sucrose ester in Group I, its $\mathrm{NH}_{4}^{+}$adduct, the glucose fragment which now does not contain an acetyl group, and the common fructose fragment at $\mathrm{m} / \mathrm{z} 205$ are presented in Table 1. Table 3 lists the retention time of the observed chromatographic peaks which gave rise to the 
Table 4. Chromatographic and mass spectral data for observed Group II homologs via RP-HPLC/MS: SFC fraction no. 4 - different Oriental tobaccos

\begin{tabular}{|c|c|c|c|c|c|c|c|c|}
\hline \multirow[b]{2}{*}{$\begin{array}{l}\mathrm{MM}+\mathrm{NH}_{4}{ }^{+} \\
\text {Adduct }\end{array}$} & \multirow[b]{2}{*}{$\begin{array}{c}\text { MM } \\
\text { Parent }\end{array}$} & \multirow[b]{2}{*}{$\begin{array}{l}\text { GLU-Oac } \\
\text { Fragment }\end{array}$} & \multicolumn{3}{|c|}{ Sample 1} & \multicolumn{3}{|c|}{ Sample 2} \\
\hline & & & $\begin{array}{l}t_{\mathrm{r}}, \min \\
\mathrm{PK} 1 \\
\end{array}$ & $\begin{array}{c}t_{\mathrm{r}}, \min \\
\mathrm{PK} 2 \\
\end{array}$ & $\begin{array}{l}t_{\mathrm{r}}, \min \\
\mathrm{PK} 3 \\
\end{array}$ & $\begin{array}{l}t_{r}, \min \\
\mathrm{PK} 1 \\
\end{array}$ & $\begin{array}{l}t_{\mathrm{r}}, \min \\
\mathrm{PK} 2\end{array}$ & $\begin{array}{l}t_{\mathrm{r}}, \min \\
\mathrm{PK} 3 \\
\end{array}$ \\
\hline 570 & 552 & 373 & 26.79 & 28.88 & 29.35 & 26.79 & 28.97 & 29.44 \\
\hline 584 & 566 & 387 & 28.22 & 30.31 & 30.92 & 28.24 & 30.35 & 30.92 \\
\hline 598 & 580 & 401 & 29.73 & 31.98 & 32.42 & 29.79 & 31.97 & 32.4 \\
\hline 612 & 594 & 415 & 33.36 & & & 33.33 & & \\
\hline 626 & 608 & 429 & 34.75 & & & 34.81 & & \\
\hline 640 & 622 & 443 & 35.79 & 36.22 & & 35.79 & 36.22 & \\
\hline 654 & 636 & 457 & 37.37 & 37.82 & & 37.34 & 37.81 & \\
\hline 668 & 650 & 471 & 37.19 & & & 37.13 & & \\
\hline 682 & 664 & 485 & 38.77 & & & 38.67 & & \\
\hline 696 & 678 & 499 & 40.24 & & & 40.24 & & \\
\hline \multicolumn{3}{|c|}{ Sample 3} & \multicolumn{3}{|c|}{ Sample 4} & \multicolumn{3}{|c|}{ Sample 5} \\
\hline $\begin{array}{l}t_{\mathrm{r}}, \min \\
\mathrm{PK} 1\end{array}$ & $\begin{array}{l}t_{\mathrm{r}}, \min \\
\mathrm{PK} 2 \\
\end{array}$ & $\begin{array}{l}t_{\mathrm{r}}, \min \\
\mathrm{PK} 3\end{array}$ & $\begin{array}{l}t_{\mathrm{r}}, \min \\
\mathrm{PK} 1\end{array}$ & $\begin{array}{l}t_{\mathrm{r}}, \min \\
\mathrm{PK} 2\end{array}$ & $\begin{array}{l}t_{\mathrm{r}}, \min \\
\mathrm{PK} 3\end{array}$ & $\begin{array}{l}t_{\mathrm{r}}, \min \\
\mathrm{PK} 1\end{array}$ & $\begin{array}{l}t_{\mathrm{r}}, \min \\
\mathrm{PK} 2\end{array}$ & $\begin{array}{l}t_{\mathrm{r}}, \min \\
\mathrm{PK} 3\end{array}$ \\
\hline 26.75 & 28.92 & 29.44 & 26.67 & 28.95 & 29.44 & 26.79 & 28.94 & 29.46 \\
\hline 28.22 & 30.35 & 30.96 & 28.27 & 30.35 & 30.95 & 28.29 & 30.33 & 29.94 \\
\hline 29.77 & 31.91 & 32.42 & 29.77 & 31.99 & 32.44 & 29.74 & 31.98 & 32.41 \\
\hline 32.95 & 33.38 & & 32.98 & 33.42 & & 33.02 & 33.42 & \\
\hline 34.38 & 34.83 & & 34.40 & 34.83 & & 34.36 & 34.85 & \\
\hline 35.84 & 36.21 & & 35.88 & 36.30 & & 35.86 & 36.23 & \\
\hline 37.31 & 37.78 & & 37.36 & 37.80 & & 37.33 & 37.78 & \\
\hline 37.15 & & & 37.17 & & & 37.19 & & \\
\hline 38.69 & & & 38.76 & & & 38.74 & & \\
\hline 40.17 & & & 40.26 & & & 40.31 & & \\
\hline
\end{tabular}

mass spectral information. The mass spectrum of each identified peak in this second homologous series exhibited the expected $\mathrm{m} / \mathrm{z} 205$ which corresponded to fructose with an associated acetyl function. It is important to note here that these Group I sucrose esters (based upon this and previous studies) seemingly always co-elute with the Group III sucrose esters regardless of the mode of initial extraction, pre-separation, or analytical separation. In other words, separation via SFC of underivatized sucrose esters, GC of derivatized sucrose esters, and RP-HPLC of underivatized esters all revealed co-elution of Groups I and III. A minimum of six Group I chromatographic peaks were observed with parent $\mathrm{m} / \mathrm{z} 608,626,664,678,692$, 706 , and 720 which could be readily assigned to the $\mathrm{NH}_{4}^{+}$ adduct of the respective sucrose ester. It was concluded in our previous publications where extraction was accomplished via conventional solvents and further fractionation was achieved via normal phase HPLC, that the minimum number of fatty acid ester acyl carbons was 17; while in this research where extraction was accomplished via supercritical $\mathrm{CO}_{2}$ and further fractionation was achieved via SFC with modified carbon dioxide we were able to detect as low as 13 fatty acid ester carbons. The data in Tables 2 and 3 also point to additional molecular weight/structural isomerization within Group III and Group I sucrose esters. For example, in Table 2, the molecular mass parent ion $\mathrm{m} / \mathrm{z}=580$, appears at $t_{\mathrm{r}}=31.97$ min only in sample no. 2. Likewise, the molecular mass parent ion $m / z=580$, appears at $t_{\mathrm{r}}=32.42 \mathrm{~min}$ in all samples except no. 1. Furthermore, for example, Table 3, the molecular mass parent ion $m / z=678$ appears around $t_{\mathrm{r}}$ $=\sim 38$ min for samples no. 1 and no. 2 , but appears at $t_{\mathrm{r}}=$ $\sim 39.6$ min for samples no. 3-5. In addition, the molecular mass parent ion $\mathrm{m} / \mathrm{z}=664$, appears at $t_{\mathrm{r}}=\sim 33.5 \mathrm{~min}$ for samples no. 1 and no. 2, but appears at $t_{\mathrm{r}}=38.85 \mathrm{~min}$ for sample no. 4 at $t_{\mathrm{r}}=38.18 \mathrm{~min}$ for sample no. 5 . These shifts in retention time with accompanying constant molecular mass values strongly suggest additional structural isomerization among the Group III and Group I sucrose esters.

Next, analysis of SFC fraction no. 4 via RP-HPLC/MS was performed. The total ion chromatogram is shown in Figure 12B. This fraction seemingly contained no evidence of either Groups I or III. The data, however, yielded a good match for Group II sucrose esters. Table 4 shows the mono-isotopic mass of each parent Group II sucrose ester, its $\mathrm{NH}_{4}^{+}$adduct, the glucose fragment which in this case carries the acyl groups but not the acetyl group, and the measured retention time of the eluted peak corresponding to each parent ion in the extracted ion mode. The lowest detectable $m / z$ adduct in Group II in SFC fraction 4 was 570 and the highest $\mathrm{m} / \mathrm{z}$ adduct was found at 696. It is important to note here that no mass spectra of peaks described in Table 4 showed the presence of $m / z 205$ which would have corresponded to fructose with an acetyl group. As far as the glucose fragments $\mathrm{m} / \mathrm{z}$ are concerned, they varied with the homologous series. For some $m / z$ values arising from this fraction, more than one chromatographic peak was observed which suggested an extensive degree of substitutional isomerism among the constituents. This extensive degree of substitutional isomerization was more substantial than that found for the Group III and Group I sucrose esters, vide supra. Illustrations of this observation chromatographically are shown in Figure 13 where the top 


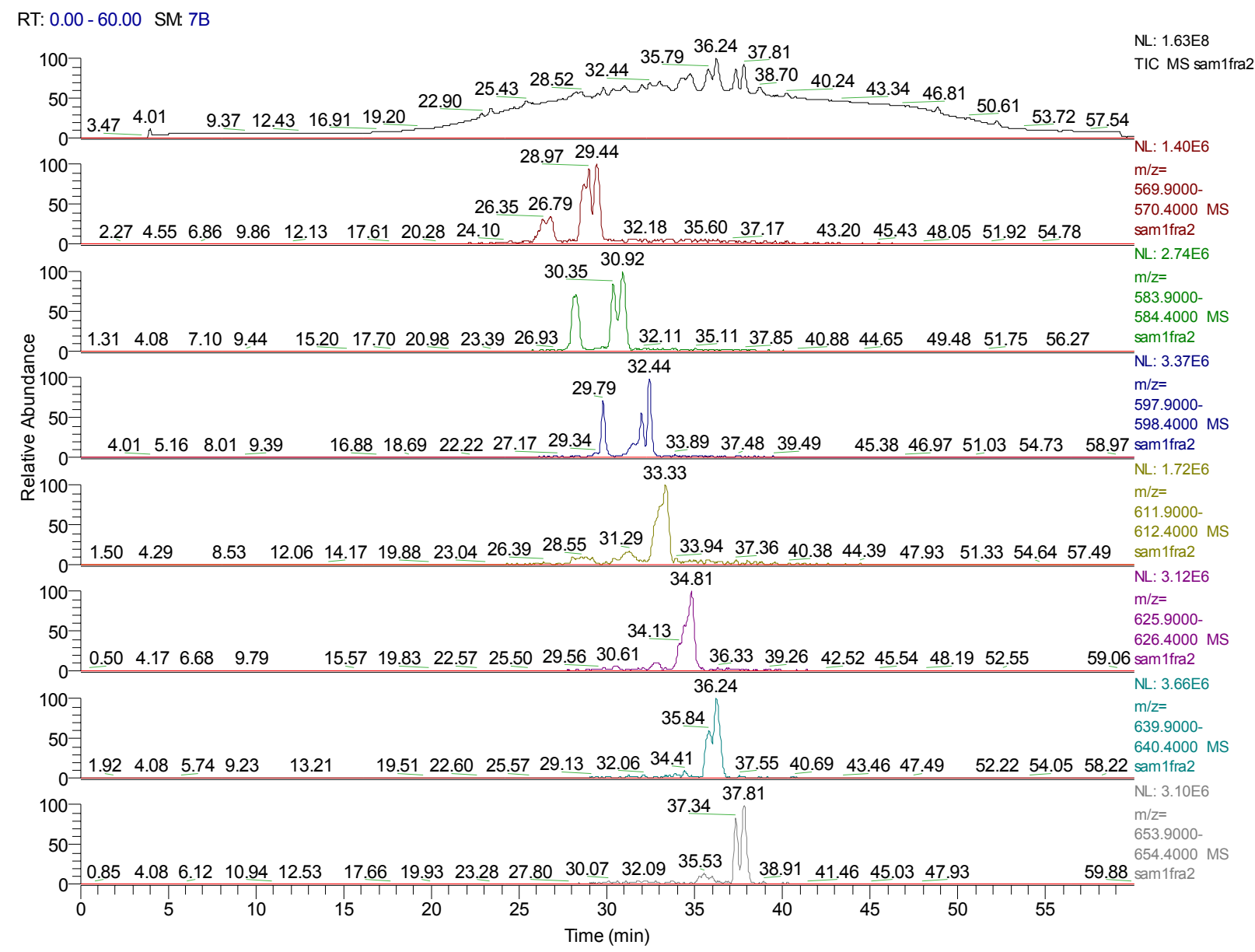

Figure 13. Selected extracted ion chromatograms of Group II sucrose esters from SFC fraction no. 4

trace corresponds to the TIC and lower traces are for the selected ions that are listed on each chromatogram. The trend to longer retention times with molecular mass is readily apparent and indicative of the trend to increasing hydrophobicity of each homolog that is separated via reversed phase chromatography. Isomerism seemed to be more prevalent for this Group as each of the five tobacco samples exhibited more than one peak for most monitored masses. The fact that the incidence of multiple peaks is universally observed for the lower masses (i.e. parent $\mathrm{m} / \mathrm{z}$ 552 to 580) is noteworthy. As noted above with the Group III and Group I sucrose esters, additional substitutional isomers are denoted in Table 4 . Note that the $t_{\mathrm{r}}$ for molecular mass parent $m / z=594$ is unique for samples no. 3,4 , and 5 . A similar pattern can be found at $t_{r}=\sim 34.4$ min for molecular mass parent $m / z 608$ in samples no. 3, 4, and 5 .

The presence of unsaturation within the fatty acid groups is apparent upon inspection of Table 5 for Group II sucrose esters. Adduct, parent, and glucose fragment exhibit $\mathrm{m} / \mathrm{z}$ ratios that are two mass units lower than the comparable data for the saturated analogs shown in Table 4. The assignment of these unsaturated homologs to Group II is supported by the appearance of the common $\mathrm{m} / \mathrm{z} 163$ which is in agreement with a fructose fragment with no acetyl group attached. It is interesting to note that the unsaturated species are exclusively observed for the highest homologs (i.e. parent masses $m / z 634$ to 676,
Table 4). Two closely eluting peaks were observed for each molecular mass monitored. Analysis of the fatty acid components would have been interesting to discover the specific site of unsaturation and to ascertain if the site of unsaturation varied from one fatty acid to another or was the unsaturation at different sites with the same fatty acid. No evidence for unsaturation could be found for Groups I and III. Furthermore, sites of multiple unsaturation in Group II sucrose esters could not be substantiated.

In conclusion, we feel that the use of supercritical fluid $\mathrm{CO}_{2}$ to characterize sucrose esters affords many advantages over conventional solvents not only for initial extraction of the sucrose ester from the tobacco but also for isolation of highly specific groups of sucrose ester- enriched fractions via SFC for later analysis using RP-HPLC/MS. The initial extraction step is greatly simplified in that pre-extraction at low carbon dioxide density removes many interfering components. With liquid extraction, the sucrose esters and other co-extractives are mixed. In this case, extensive sample clean-up is required. With carbon dioxide, sample clean up is not necessary. Thus, a crude sucrose ester extract is achievable at an easily accessed higher density with no multiple solvent partitioning/evaporation steps that are required in the older methodologies. Semi-preparative SFC employs minimal organic solvent for enhanced product purity and concomitant isolation of homologous mixtures via simple carbon dioxide depressurization at room temperature. In the older protocols, normal phase 
Table 5. Chromatographic and mass spectral data (MM) for observed unsaturated group II sucrose ester homologs via RPHPLC/MS: SFC fraction no. 4 - different Oriental tobaccos

\begin{tabular}{|c|c|c|c|c|c|c|c|c|c|c|c|c|}
\hline \multirow[b]{2}{*}{$\begin{array}{l}\left(\mathrm{MM}+\mathrm{NH}_{4}\right)^{+} \\
\text {Adduct }\end{array}$} & \multirow[b]{2}{*}{$\begin{array}{c}\text { MM } \\
\text { Parent }\end{array}$} & \multirow[b]{2}{*}{$\begin{array}{l}\text { GLU-OAc } \\
\text { Fragment } \\
\end{array}$} & \multicolumn{2}{|c|}{ Sample 1} & \multicolumn{2}{|c|}{ Sample 2} & \multicolumn{2}{|c|}{ Sample 3} & \multicolumn{2}{|c|}{ Sample 4} & \multicolumn{2}{|c|}{ Sample 5} \\
\hline & & & $\begin{array}{l}t_{\mathrm{r}}, \min \\
\mathrm{PK} 1\end{array}$ & $\begin{array}{l}t_{\mathrm{r}}, \min \\
\mathrm{PK} 2\end{array}$ & $\begin{array}{l}t_{\mathrm{r}}, \min \\
\mathrm{PK} 1\end{array}$ & $\begin{array}{l}t_{\mathrm{r}}, \min \\
\mathrm{PK} 2\end{array}$ & $\begin{array}{l}t_{\mathrm{r}}, \min \\
\mathrm{PK} 1\end{array}$ & $\begin{array}{l}t_{\mathrm{r}}, \min \\
\mathrm{PK} 2\end{array}$ & $\begin{array}{l}t_{\mathrm{r}}, \min \\
\mathrm{PK} 1\end{array}$ & $\begin{array}{l}t_{\mathrm{r}}, \min \\
\mathrm{PK} 2\end{array}$ & $\begin{array}{l}t_{\mathrm{r}}, \min \\
\mathrm{PK} 1\end{array}$ & $\begin{array}{l}t_{\mathrm{r}}, \min \\
\mathrm{PK} 2 \\
\end{array}$ \\
\hline 652 & 634 & 455 & 34.17 & 34.74 & 34.19 & 34.76 & 34.22 & 34.78 & 34.24 & 34.80 & 34.24 & 34.78 \\
\hline 666 & 648 & 469 & 35.37 & 36.19 & 35.38 & 36.22 & 35.39 & 36.28 & 35.60 & 36.26 & 35.41 & 36.23 \\
\hline 680 & 662 & 483 & 36.85 & 37.64 & 36.75 & 37.62 & 36.91 & 37.66 & 36.96 & 37.73 & 36.98 & 37.69 \\
\hline 694 & 676 & 497 & 38.28 & 39.12 & 38.18 & 39.24 & 38.32 & 39.12 & 38.34 & 39.19 & 38.34 & 39.16 \\
\hline
\end{tabular}

chromatography with polar mobile phases that were sensitive to traces of water was used to facilitate this later fractionation. SFC is a more robust, faster normal phase method wherein traces of water are not critical. Elimination of solvent is spontaneous and scale-up to preparative chromatography is easily accomplished via SFC. Finally, identification of the sucrose esters via MS can be achieved on the underivatized analyte since there is less interference from co-extractives.

Furthermore, the sucrose ester isolates from supercritical fluid $\mathrm{CO}_{2}$ extraction have many of the structural features traditionally associated with sucrose esters from Nicotiana tabacum. That is, substitutional isomers of relatively low molecular weight carboxylic acids as functional groups on the sucrose ester backbone are present. In addition, the presence of unsaturated substitutional isomerization was also noted for one type of sucrose ester. Analyses of the supercritical fluid $\mathrm{CO}_{2}$ isolates indicated a significant diversity in molecular isomerization with selected Oriental tobaccos, with an accompanying relatively wide range in sucrose ester concentration as a function of Oriental tobacco sample.

\section{ACKNOWLEDGMENTS}

This research was support by a monetary gift to the Department of Chemistry from R. J. Reynolds Tobacco Company. Dr. Mehdi Ashraf-Khorassani was selected as an RJRT-Harold McNair Fellow in 2004.

\section{REFERENCES}

1. Schumacher, J.N.: The isolation of $6-O$-acetyl-2,3,4,tri-O-((+)-3-methylvaleryl)-beta-D-glucopyranose from tobacco; Carbohyd. Res. 13 (1970) 1-8.

2. Leffingwell, J.C. and D. Leffingwell: Chemical and sensory aspects of tobacco flavor; Rec. Adv. Tob. Sci. 14 (1988) 169-218.

3. Severson, R.F., A.W. Johnson, and D.M. Jackson: Cuticular constituents of tobacco: factors affecting their production and their role in insect and disease resistance and smoke quality; Rec. Adv. Tob. Sci. 11 (1985) 105-173.

4. Matsuzki, T., Y. Shinozaki, S. Suhara, M. Ninomiya, H. Shigematsu, and A. Koiwai: Isolation of glycolipids from the surface lipids of Nicotiana bigelovii and their distribution in Nicotiana species; Agric. Biol. Chem. 53 (1989) 3079-3082.
5. Severson, R.F., R.F. Arrendale, O.T. Chortyk, C.R. Green, F.A. Thomas, J.L. Stewart, and A.W. Johnson: Isolation and characterization of sucrose esters of the cuticular waxes of green tobacco leaf; J. Agric. Food Chem. 33 (1985) 870-875.

6. Arrendale, R.F., R.F. Severson, V.A. Sisson, C.E. Costello, J.A. Leary, D.S. Himmelsback, and H. van Halbeek: Characterization of the sucrose ester fraction from Nicotiana glutinosa; J. Agric. Food Chem. 38 (1990) 75-85.

7. Matsuzki, T., K. Koseki, and A. Koiwai: Germination and growth inhibition of surface lipids from Nicotiana species and identification of sucrose esters; Agric. Biol. Chem. 52 (1988) 1889-1897.

8. Matsuzki, T., Y. Shinozaki, S. Suhara, H. Shigematsu, and A. Koiwai: Isolation and characterization of tetraand triacylglucose of Nicotiana miersii; Agric. Biol. Chem. 53 (1989) 3343-3345.

9. Matsuzki, T., Y. Shinozaki, S. Suhara, T. Tobita, H. Shigematsu, and A. Koiwai: Leaf surface glycolipids from Nicotiana acuminata and Nicotiana pauciflora: Agric. Biol. Chem. 55 (1991) 1417-1419.

10. Shinozaki, Y., T. Matsuzaki, S. Suhara, T. Tobita, H. Shigematsu, and A. Koiwai: New types of glycolipids from the surface lipids of Nicotiana umbratica; Agric. Biol. Chem. 55 (1991) 751-756.

11. Shinozaki, Y., T. Matsuzaki, H. Suzuki, H. Shigematsu, and A. Koiwai: Surface glycolipids in shootforming culture of Nicotiana umbratica; Biosci. Biotech. Biochem. 56 (1992) 1482-1483.

12. Matsuzaki, T., Y. Shinozaki, M. Hagimori, T. Tobita, H. Shigematsu, and A. Koiwai: Novel glycerolipids and glycolipids from the surface lipids of Nicotiana benthamiana; Biosci. Biotech. Biochem. 56 (1992) 1565-1569.

13. Buta, J.G., W.R. Lusby, J.W. Neal, R.M. Waters, and G.W. Pittarelli: Sucrose esters from Nicotiana gossei active against the greenhouse whitefly trialeuroides vaporariorum; Phytochemistry 32 (1993) 859-864.

14. Severson, R.F., D.M. Jackson, A.W. Johnson, V.A. Sisson, and M.G. Stephenson: Ovipositional behavior of tobacco budworm and tobacco hormworm; in: Natural and Engineered Pest Management Agents, edited by P. Hedin, ACS Symp. Ser. 551, 1991, pp. 172-179.

15. Kandra, L. and G.J. Wagner: Studies of the site and mode of biosynthesis of tobacco trichrome exudates component; Archives Biochem. Biophys. 265 (1988) 425-432.

16. Danehower, D.A.: A rapid method for the isolation and 
quantification of the sucrose esters of tobacco; Tob. Intl. 189 (1987) 30-33.

17. Einolf, W.N. and W.H. Chan: Estimation of sucrose esters in tobacco by direct chemical ionization mass spectrometry; J. Agric. Food Chem. 32 (1984) 785-789.

18. Ashraf-Khorassani, M., N. Nazem, L.T. Taylor, and W.M. Coleman III: Separation and identification of sucrose esters from Turkish tobacco using liquid chromatography-mass spectrometry; Beitr. Tabakforsch. Int. 21 (2005) 380-389.

19. Ashraf-Khorassani, M., N. Nazem, L.T. Taylor, and W.M. Coleman III: Identification and quantification of sucrose esters in various Turkish tobaccos; Beitr. Tabakforsch. Int. 21 (2005) 441-450.

20. Ashraf-Khorassani, M., N. Nazem, L.T. Taylor, and W.M. Coleman III: Isolation of tetra-acyl sucrose esters from Turkish tobacco using supercritical carbon dioxide and comparison with conventional solvent extraction; J. Agric. Food Chem. 53 (2005) 1866-1872.

21. Severson, R.F., O.T. Chortyk, M.G. Stephenson, D.H. Akey, J.W. Neal, G.W. Pittarelli, D.M. Jackson, and V.A Sisson: Characterization of natural pesticide from Nicotiana gossei; in: Bioregulators for Crop Protection and Pest Control; ACS Symp. Ser. 557, 1994, pp. 109-121.
22. Kanda, L., R.F. Severson, G.J. Wagner: Modified branched-chain amino acid pathways give rise to acyl acids of sucrose esters exuded from tobacco leaf trichomes; Eur. J. Biochem. 188 (1990) 385-394.

23. Leffingwell, J.C.: Leaf chemistry; in: Tobacco Production, Chemistry, and Technology; edited by D.L. Davis, and M.T. Nielson, Blackwell Science, Oxford, United Kingdom, 2001, pp.265-284.

Address for correspondence:

Larry T. Taylor

Department of Chemistry

Virginia Tech Blacksburg

VA 24061-0212

USA

E-mail: ltaylor@vt.edu 